\title{
Academic Stress and Drug Abuse as Factors Inhibiting Psychological Well-Being Among Undergraduates: It's Counselling Implications
}

\author{
Dr.(Mrs.) Bukoye, Roseline Olufunke \\ Department Of Counselling Psychology, \\ Ibrahim Badamasi Babangida (Ibb) University, Niger State, Nigeria
}

doi: 10.19044/esj.2017.v13n8p60 URL:http://dx.doi.org/10.19044/esj.2017.v13n8p60

\begin{abstract}
The study examined Academic Stress and drug abuse as factors inhibiting psychological well-being among undergraduate students and its counselling implications. Three faculties in IBB University were purposively selected for the study and 90 students were randomly selected in the three faculties for the study. Three instruments (PPPWQ, ASRS. and DAST.) that were validated by experts and with confirmed reliabilities were used for the study. Each instrument was administered on the respondents and retrieved by the researcher with the efforts of 3 research assistants.Simple percentage, Rank order and chi-square were used for bio-data and the analysis of data respectively. The findings revealed that, lack of time management, text anxiety, uncoverage of course contents and difficult in course component are the causes of academic stress among students. The intake of drugs makes the students feel lonely, sexual urge, Bullying, poor Odour, among others, Sweating, accelerated heart rate, trembling, maladjustment, fear of failure, among others are the nasty effects of academic stress and drug abuse on their personalities as such, inhibiting their psychological well-being. It was vividly seen that academic stress and drug abuse are significant factors that inhibit psychological well-being of students. Based on the findings, the counsellor could use systematic desensitization technique to discourage drug use among students and seminars, advocacy programmes, among others, are recommended to help the students.
\end{abstract}

Keywords: Academic Stress, Drug Abuse, Inhibiting, Psychological, WellBeing

\section{Introduction}

Stress is a common phenomenon in all societies as it is part of everyday living and activities. Stress according to Saka (2010) is defined as 
body reactions to pressure or response to perceived or actual danger. Stress is very serious among students in academic environment as emphasized by some researchers and educationist. The former Nigerian minister of education prof. JubrilAminu who said that, inadequate and irrelevant studying materials for studying, un-conducive studying environment, non payment of salaries and allowances, constant and prolonged strikes by teachers, uncertainty of jobs after school, academic failure, uncoverage of syllabus, frustration among others. These resulted and endanger a deep feeling of anxiety and confusion in students.Academic stress According to Oduoye (2011) is a negative emotional experience, accompanied by educational instability by predicted psychological, cognitive and behavoural change of the students that are directed either toward altering their academic circumstances or accommodating to its effects. This in the long run influences the students'well-being. Academic stress is the discomfort in the body equilibrium resulting from stressors experienced from too many school assignments, competition with other students, inadequate consideration of students' individual differences by the lecturers or teachers, lack of adequate academic supports from parents and other significant others, academic failure and lack of money for upkeep.

From Warn (2003) academic stress affecting students can be categorized as academic failure, in appropriate time to finish class work, health related and self-imposed activities. Other type of academic stress as emphasized by Frazer (2011) include student perception of extensive school activities, inadequate academic facilities, inadequate social amenities in academic environment, among others.

Academic stress in higher institutions in Nigeria is at increase due to prolonged strikes resulting to shut-down of school, lack of financial back up for students and economic hardship currently experienced in Nigeria as a result of economic and political instability. These problems put together have compelled students to take to irrational behaviours such as, involvement in secret Cults activities, imbibing in drug abuse, examination malpractice and other forms of hedonism (Yahaya, 1998). This was in line with Payne (2000) assertion that, academic activities in developed economy such as America could be tasking and therefore lead to eroneousbehaviour and stress; how much more so would students' activities of a developing and depressed economy like Nigeria would not experience a greater degree of stress under the circumstances in which they found themselves. When academic stress is perceived negatively become excessive, student experience physical and psychological impairment which later resulted to maladaptive behaviours such as bullying, drug abuse, among others (Murphy, 2010).

Oyeyemi (2008) said that, most Nigerian students suffered academic stress resulting from rapid exposure to and acceptance of foreign cultural 
views and values, without adequate understanding and interpretation of their own cultural heritage as such, have adverse effects on their psychological adjustment. According to Blake Vandiver(2000) and Kessler (2009) the method used to reduce academic stress by students often include effective time management, social supports, positive reappraisaland use of drugs and abuse of drugs.

According to Walters (2001) drugs are integral parts of a chosen lifestyle. Drug abuse by young peoples is rooted in personal attitudes and values are noticed in their relationship with people and their peers. According to Bukoye (2004) drug abuse is the misuse of drugs. That is, the use of drugs not prescribed by medical experts. Ndu (2002) sees drug abuse as the indiscriminate use of drug. By self-administration of any drug in a manner that deviate from the approved medical or social pattern within a given culture is seen as abused of drug.

The students' drug use and its abuse takes place in a psychological context that is probably the dominant force determining why, where how and what drugs are abused. Some drug addicted students use drugs openly and in combinations of other drugs in large amounts so that, they become publicly wild or crazy in facing challenges that come over them.

If we view it in another perspective one may say, the period of adolescence may be associated with increased vulnerability to drug dependence because that age period is characterized by:

$\checkmark$ Increased frequency of mood swingsand depressive reaction;

$\checkmark$ An increase in social sensitivities that create problems requiring isolation if the person is to mature;

$\checkmark$ Increased loneliness; boredom, and striving for independence and identity formation, and

$\checkmark$ Increased peer influence on peer group members.

From Ige(1990) the period of adolescence is marked by problems, many of which are brought about by the changes taking place in the young students and his efforts at adjusting to these changes. Some of the time, students are confused and their efforts at adjusting to these changes lead to frustration and general derangement hence maladaptivebehaviours like drug abuse, secret cult, smoking of cigarette, keeping late night, among others.

Features of drug abuse: -Behavioural changes may suggest drug abuse in students.

These include absence from school and academic failure. Causes of drug abuse include: too much of stress on the body, academic activities, personality disorder, poor school records, truancy, inability to cope with challenges of life, depression, anxiety, among others. Some drugs that are commonly abused by students include; alcohol, narcotics, cocaine, Indian 
helm, among others. All these have adverse effects on students' psychological well-being.

Psychological well-being appears to be relatively broad concept. According to Baron (1998) the most important reliable factorial components of psychological well-being are self-regards, interpersonal relationships, independence, and problem solving, assertiveness, reality and stress tolerance.

The random house dictionary of the English Language (1967) defined well-being as a good satisfactory condition of coexistence, a state characterized by health, happiness and prosperity. The term psychological well-being is often interchanged with mental health and when it is done so, it designates one who is functioning at a high level of behavioural and emotional adjustment and adaptiveness, and not who is simply not ill (Reber and Reber, 2001). Psychological well-being is associated with variety of concepts namely: life satisfaction, happiness, adjustment, morale and subjective well-being (Ryffi, 1989) anything or factor sort of this, bring about psychological imbalance or problems. It is also referred to as emotional, social and intellectual fitness of the mind and body. Constant and unresolved academic stress and intake of un-prescribed drugs mostly lead to psychological imbalance (Murphy, 2010).

Too much of stress on students in academic environment and excesses abuse of substance has nasty and devastating effects on the student's psychological well-being.

\section{Statement of problems}

Many students are in trouble today by emotional and academic problems emanated from psychological inbalance. Excessive intake of drugs and stress has led many (45\%) of students into aggressive, restive bahaviour, lack the social skills required to solve problems appropriately. Some students could not take responsibility for their own actions and have no ability to express their feelings (Torubeli, 2010). From survey made by Glick (1996) with 150 engineering students of level two students with 35\% of these students exhibited violence tendency, signs of withdrawal, feelings of inferiority, anxiety and over-sensitivity to teasing and criticism, while $20 \%$ of engineering students with sign of drugs intakes were found to be maladjusted, personality disorder, low self-esteem and poor cognitive ability. These have adverse effects on students, hence their well-being and academic performance were affected.

Also, some young people nowadays are often enticed by drug as such, tend to become peddlers and consume illegal substances. According to Ryan (2009) 30\% of people that take drugs like marijuana, Heroin, cocaine, among others take it to gain autonomy, relatedness, competence and to relief 
them out of stress. When the objectives fail or otherwise, their psychosocial well-being is thwarting, ends in frustration and greater ill-being resulted. From Kobasa (2009) 35\% of students who are academically stressed experienced psychological hardiness, personality hardiness, or cognitive hardiness. They are under life stress, as compared to other 65\% who develop series of health problems. Pinto (1994) and Visser (2008) opined that, academic stress encountered by students affect their academic performance, physical health and psychological competence. Coping efforts classified by engagement strategies of $50 \%$ of such students were associated with fever depressive symptoms, while coping efforts classified by disengagement strategies of the remaining $50 \%$ of such students were associated with levels of depressive symptoms (Imeh, 2014).

The conclusion here,is that, academic stress and its different aspects exert negative impacts on psychological well-being of the students; as such, needs urgent attention.

\section{Research questions}

- Is drug abuse a factor of psychological well-being?

- How does academic stress affect the psychological well-being of students?

- Does academic stress a factor of psychological well-being?

- What are the causes of academic stress on students?

\section{Research hypotheses}

- Academic stress is a significant factor of psychological well-being.

- Drug abuse is a significant factor of psychological well-being of the students.

\section{Purpose of study}

- The purpose of the study is to identify if academic stress and drug abuse factors inhibit psychological well-being among undergraduates or not.

- To identify the possible causes of academic stress in undergraduates.

- To identify the causes of drug abuse on undergraduates.

\section{Research methodology}

The survey design was used to accomplish the purpose of the study. The population for the study consisted of male and female students of Ibrahim BadamasiBabangida(IBB) University, Lapai, Niger state. Three faculties (education and arts, management and social sciences and natural sciences) were purposely selected for the study. Thirty (30) students 
(comprising 15 males and 15 females) were randomly chosen from each of the faculties, making the total number of students to be 90 students.

\section{Research instrument}

$\checkmark \quad$ An instrument perceived psychological well-being Questionnaire (PPWQ) was constructed by the researcher, restructured by two experts before the final prints was used to collect data. The instrument has 16 items constructed with a 4 points liker scale of Strongly agree, Agree. Disagree and Strongly disagree. The instrument has two sections A and B. section A was for the respondents' bio data, while section B consisted of 16 items responding to respondents' psychological well-being.

The reliability of the PPWQ was established through test re-test method with 20 undergraduate students. The instrument was administered twice within 2 weeks interval. The two results were correlated using PearsonProduct Moment Correction. A Coefficient of 0.72 was got. It was considered high enough.

$\checkmark \quad$ Academic stress response scale (ASRS) academic stress response scale developed by Lakaeve (2006) wasadopted to measure students'academic stress. The instrument has 25 items but the first 14 items was adopted because of their relevance to the purpose. The ASRS has a response format of Very much, Much, Little, Very little.

The scale was purported to measure the level of undergraduates academic stress, it under went another level of restructuring by two experts before the use of its final prints.

The reliability was confirmed using slipthalf method. The instrument was administered on 20 students. Responses in odd and even numbers were scored separately. The two scores were correlated using pearsonr correlation coefficient. Coefficient of 0.77 was got indicating the reliability was high enough.

$\checkmark \quad$ The drug abuse screening test (DAST) Drug Abuse Screening Test (DAST) was developed by Shinner (1982). It was designed to provide a brief instrument for measuring drug abuse and evaluation research. The DAST relevant 10 iterms were adopted.The answer options for each item was "Yes" or "No". The DAST total scores were computed by summing all the items that are endorsed in direction of increased drug use problem. This instrument was restructured by two experts before the final reprints. The reliability was reconfirmed through the test re-test method with an interval of two weeks on the undergraduates identified using drugs. Tests re-test reliability yielded a co- efficient of 0.87 . 


\section{Method of data analysis}

Simple percentage was used for the respondents'bio data, Bar chart was used to confirm the academic stress, mean and rank order was used for level of drug abuse and students psychological well-being. While chi-square statistical analysis was used for the formulated hypotheses.

\section{Results}

Table 1: showing the Distribution of Respondents by Faculties.

\begin{tabular}{|c|c|c|c|c|c|}
\hline Variables & $\begin{array}{c}\text { Education } \\
\text { and arts }\end{array}$ & $\begin{array}{c}\text { Management } \\
\text { \& Social Sci. }\end{array}$ & $\begin{array}{c}\text { Natural } \\
\text { Science }\end{array}$ & Total & Percentage \\
\hline Males & 15 & 15 & 15 & 45 & $50 \%$ \\
Females & 15 & 15 & 15 & 45 & $50 \%$ \\
\hline TOTAL & 30 & 30 & 30 & 90 & $100 \%$ \\
\hline
\end{tabular}

Table1, revealed that, both students gender were equally represented in the study. The total populations of male respondents were 45 (50\%) and that of female student respondents were 45 (50\%).

Table 2: showing Bar Chart representing the causes of academic stress among others:

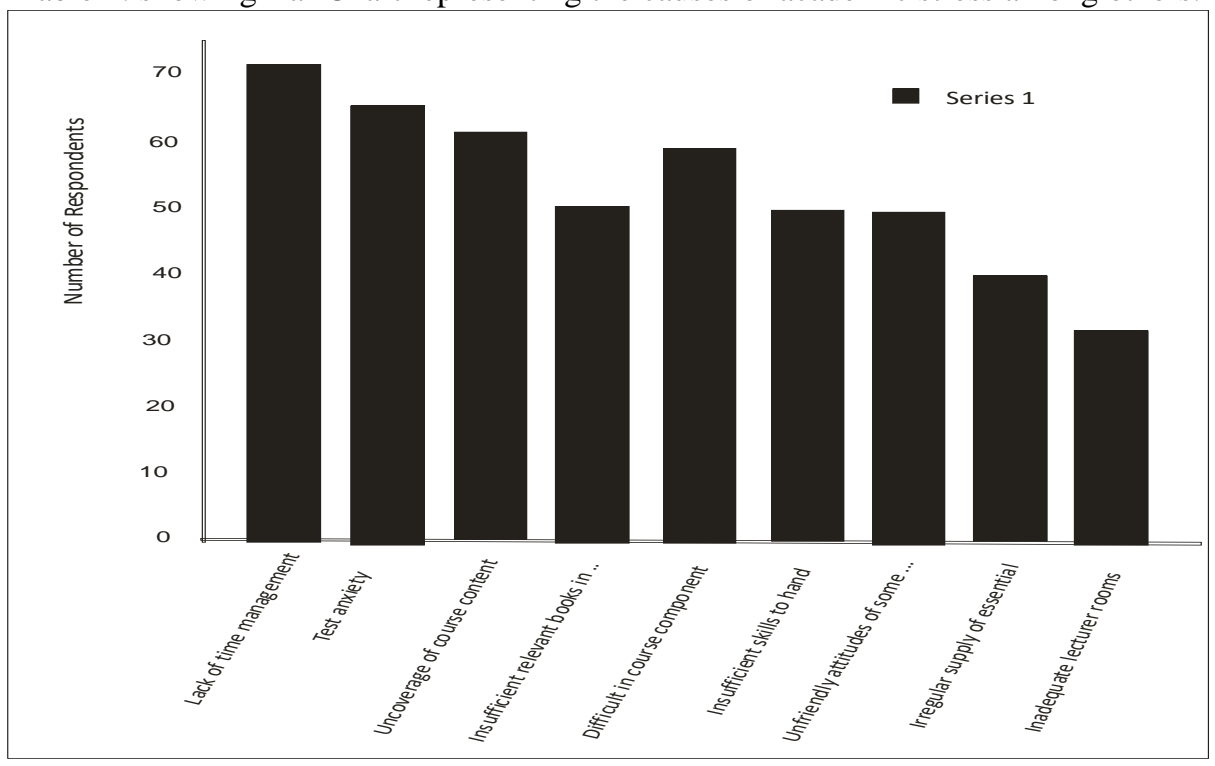

The data represented in table 2 showed that out of 90students involved in the study, 70 (77.8\%) emphasized lack of the management as their source of academic stress, while 65 (72.2\%), 62 (68.0\%), 50 (55.6\%), 60 (66.7\%), 50 (55.6\%), 50 (55.6\%), 40 (44.4\%) and 35 (38.9\%) of the total respondents mentioned text anxiety, uncoverage of course content, insufficient of relevant text books in the library, difficulty in course component, irregular supply of essential facilities like water, light and 
inadequate lecture rooms respectively were identified as their major causes of academic stress and which also induced them to taking drugs.

Table 3 showing effects of drug abuse on the students of drugs intake

\begin{tabular}{|c|c|c|c|c|}
\hline S/N & Whenever I take drugs due to Stress, I feel: & $\begin{array}{c}\text { MEAN } \\
(\times)\end{array}$ & Decisions & $\begin{array}{c}\text { Rank } \\
\text { order }\end{array}$ \\
\hline 1. & Lonely & 3.89 & Agree & $1^{\text {st }}$ \\
2. & Arousal of Sexual urge & 3.72 & Agree & $2^{\text {nd }}$ \\
3. & Bullying & 3.69 & Agree & $3^{\text {rd }}$ \\
4. & Poor interference with my teachers & 3.56 & Agree & $4^{\text {th }}$ \\
5. & Body odour & 3.55 & Agree & $5^{\text {th }}$ \\
6. & Regression & 3.32 & Agree & $6^{\text {th }}$ \\
7. & Naggings anybody around me & 3.00 & Agree & $7^{\text {th }}$ \\
8. & Instant discomfort & 2.50 & Agree & $8^{\text {th }}$ \\
9. & Deterioration of my health & 2.40 & Disagree & $9^{\text {th }}$ \\
10. & Poor perception of life & 2.20 & Disagree & $10^{\text {th }}$ \\
\hline
\end{tabular}

Table 3 showed the mean and rank order of drug abuse as factor of influence on students Eight(8) items exceeded the acceptance level of 2.50. This means all the respondents agreed to the items as havingeffect, on their psychological well-being except items 9 and 10 with lower means which were not seen as having significant influence on their well-being.

Table 4 showing academic stress and drug abuse as factors inhibiting the students' psychological well-being.

\begin{tabular}{|c|c|c|c|c|}
\hline S/N & $\begin{array}{c}\text { My state of personality resulting from } \\
\text { academic stress or drug abuse include: }\end{array}$ & Mean (x) & Decisions & $\begin{array}{c}\text { Rank } \\
\text { order }\end{array}$ \\
\hline 1. & Sweating & 3.84 & Agree & $1^{\text {st }}$ \\
2. & Accelerated heart rate & 3.72 & Agree & $2^{\text {nd }}$ \\
3. & Trembling & 3.66 & Agree & $4^{\text {th }}$ \\
4. & Fear of failure & 3.80 & Agree & $3^{\text {rd }}$ \\
5. & Maladjustment & 3.60 & Agree & $5^{\text {th }}$ \\
6. & Feeling of choking & 3.34 & Agree & $6^{\text {th }}$ \\
7. & Discomfort & 3.31 & Agree & $7^{\text {th }}$ \\
8. & Chest pains & 2.94 & Agree & $8^{\text {th }}$ \\
9. & Ansteady & 2.71 & Agree & $9^{\text {th }}$ \\
10. & Heat sensation & 2.61 & Agree & $10^{\text {th }}$ \\
11. & Derealisation (feeling of unreality) & 2.55 & Agree & $11^{\text {th }}$ \\
12. & Depersonalization (being detached from & 2.35 & Agree & $14^{\text {th }}$ \\
13. & oneself) & 2.20 & disagree & $15^{\text {th }}$ \\
14. & Fear of losing control & 2.53 & Agree & $13^{\text {th }}$ \\
15. & Suspection & 2.15 & disagree & $16^{\text {th }}$ \\
16. & Sensations of shortness of breath & & \\
\multicolumn{2}{r}{} & & & \\
\hline
\end{tabular}

Table 4 revealed that, only items 14, 15 and 16 obtained means rating below 2.50 and rated as $14^{\text {th }}, 15^{\text {th }}$ and $16^{\text {th }}$ respectively. This means that, the 
respondents disagreed that, the items do not have significant influence onstudents’ psychological well-being.

Items 1 to 5 were ranked highest as 3.84, 3.80, 3.72, 3.66 and 3.60 respectively and accepted by all respondents as having greater influence on their psychological well-being. While items 6 to 13 were ranked as next following the higher ones with mean scores of 3.34, 3.31, 3.30, 2.94, 2.71, 2.61, 2.55 and 2.53 and with rank order $6^{\text {th }}, 7^{\text {th }}, 8^{\text {th }}, 9^{\text {th }}, 10^{\text {th }}, 11^{\text {th }}, 12^{\text {th }}$ and $13^{\text {th }}$ respectively.

It was revealed that lack of management, text anxiety, uncover age of course content, unfriendly attitude of some lecturers, inability to handle work-load among others. are the highest level of academic stress experienced by students hence, have negative influence on their psychological wellbeing. The finding was in support of Frazer (2011) who emphasized that too much of stress on students could lead to deteriorating effects on students' personality stability.

The results also revealed that feeling of loneliness, arousal of sexual urge, keeping late night, poor interference, bullying, regression, among others are the outcome of drug abuse in students who adopt drugs as solution to their stress. This was in support of Ige (1990) who foundthat casualties emerge from drug abuse including damaging to physical and psychological health.

More so, sweating, accelerated heart rate, fear of failure, trembling, feeling of choking, discomfort, chest pains, maladjustment, among others are the factors of stress and drug abuse that can inflict serious effects on students' psychological well-being. The findings was in line with $\mathrm{Ndu(2002)}$ who opined that excessive stressful situation arouse behaviour problems like drug taken,which led to expressed depressive characteristics of borderline personality.

\section{Hypotheses Testing Hypothesis 1}

Academic stress is a significant factor of psychological well-being. Table 5: showing distribution of respondents according to academic stress based on faculties

\begin{tabular}{|c|c|c|c|c|}
\hline Response & Education and Arts & Management \& Social Sci. & Natural Sciences & Total \\
\hline Positive & 17 & 14 & 11 & 90 \\
\hline Negative & 13 & 16 & 19 & 90 \\
\hline Total & 30 & 30 & 30 & 90 \\
\hline
\end{tabular}

Table 5: showed the response of the respondents based on the faculties. It showed the number of respondents as they responded either positively or negatively on the basis of each faculty considered in the study as indicated in the table. 
Table 6: showing the Expected Value of Chi-square.

\begin{tabular}{|c|c|c|c|c|}
\hline Fo & Fe & Fo-Fe & $(\mathrm{Fo}-\mathrm{Fe})^{2}$ & $\frac{(\mathrm{Fo}-\mathrm{Fe})^{2}}{\mathrm{Fe}}$ \\
\hline 17 & 14 & 3 & 9 & 0.643 \\
\hline 17 & 14 & 0 & 0 & 0 \\
\hline 11 & 14 & -3 & 9 & 0.643 \\
\hline 13 & 16 & -3 & 9 & 0.643 \\
\hline 16 & 16 & 0 & 0 & 0 \\
\hline 19 & 16 & 3 & 9 & 0.563 \\
\hline \multicolumn{4}{r}{$\mathrm{X}^{2}=5.991$ (critical value) } \\
\end{tabular}

From table 6 the calculated value of $x^{2}$ value of 2.417 is less than the critical $x^{2}$ table-value of 5.991. the hypothesis $I$ is hereby rejected. Indicating that academic stress is a significant factor inhibiting psychological wellbeing of undergraduate students.

\section{Hypothesis 2}

Drug abuse is a significant factor inhibiting psychological well-being of the students.

Table 7: showing Distribution of respondents' responses to drug abuse as factor of psychological well-being based on Faculties.

\begin{tabular}{|c|c|c|c|c|}
\hline Responses & $\begin{array}{c}\text { Education and } \\
\text { Arts }\end{array}$ & $\begin{array}{c}\text { Management and } \\
\text { Social Sci. }\end{array}$ & $\begin{array}{c}\text { Natural } \\
\text { Sciences }\end{array}$ & Total \\
\hline Positive & 14 & 12 & 13 & 39 \\
\hline Negative & 16 & 18 & 17 & 51 \\
\hline Total & 30 & 30 & 30 & 90 \\
\hline
\end{tabular}

Table 7 showed the presentation of respondents in line with their responses to drug abuse based on faculties.

Table 8: showing the Expected Value of Chi-square.

\begin{tabular}{|c|c|c|c|c|}
\hline Fo & Fe & Fo $-\mathrm{Fe}$ & $(\mathrm{Fo}-\mathrm{Fe})^{2}$ & $\frac{(\mathrm{Fo}-\mathrm{Fe})^{2}}{\mathrm{Fe}}$ \\
\hline 14 & 13 & 1 & 1 & 0.077 \\
\hline 12 & 13 & -1 & 1 & 0.077 \\
\hline 13 & 13 & 0 & 0 & 0 \\
\hline 16 & 17 & -1 & 1 & 0.059 \\
\hline 18 & 17 & 1 & 1 & 0.059 \\
\hline 17 & 17 & 0 & 0 & 0 \\
\hline & & & & $£=0.272$ \\
\hline
\end{tabular}

$$
\mathrm{X}^{2}=5.991 \text { (Critical value) }
$$

Table 8 showed that the calculated $x^{2}$ - value of 0.272 is less than the critical $\mathrm{x}^{2}$ - value of 5.991 .

The hypothesis 2 is hereby rejected. The indication for this, is that, drugs abuse is a significant factor of the students' psychological well-being. 


\section{Discussion}

Hypothesis 1 revealed that Academic stress is a significant factor inhibiting psychological well-being of undergraduate students as seen in Table 1. That is, academic stress has negative effect on students. The findings was in line with the findings of $\mathrm{Li}$ and Lin (2002) who emphasized that college environmental situation and its activities exert negative impacts on psychological well-being. It was also found in the study analysis that, lack of time management, test anxiety, uncoverage course content, among others resulted to academic stress. This was in support of Grothues and Pinto (1994) whose study revealed analysis of the mental health consequences of stress in a sample of 1,038 adolescents (526 females and 512 males) carried out on how academic stress affects students' performance, physical health and psychological well-being of the students, which the recent findings also supported. One can deduce here that, academic stress if not immediately curbed, could destabilizedstudents' stability hence making them less to observe and understand their environment.

Hypothesis two also revealed a significant relationship between drug abuse and psychological well-being. The findings of this study revealed a significant relationship between drug abuse and psychological well-being. The findings is supported with Visser (2008) who found that the analysis of variance showed that adolescents who use drugs has significantly lower levels of psychological well-being and life satisfaction. It was also in line with investigation made by Abdul, Syed, Igbal and Zaman (2009) who found that, two out of every five of their respondents reported that the work at medical school wasenormous noticed that, drug abuse affected their personal health and well-being. Some of these students see alcohol and smoking as coping strategies for stress in medical students.

\section{Conclusion}

The study found that academic stress and drug are significant factors that inhibit psychological well-being. The findings have serious implications, for academic planning ofstudents at all levels. It was also found that the causes of academic stress includes lack of the management, text anxiety, uncoverage of course content, difficulty in course components, insufficient skills to handle workload, unfriendly attitudes of some lecturers, among others.

It was also found that loneliness, sexual urge, body odour, bullying, nagging, fear of failure, among others are common behaviour of students who take to drugs. While sweating accelerated heartbeat, maladjustment, trembling, discomfortderealisation, depersonalization, among others are positively responded to by students as the behavioursinhiting their psychological well-being. 
For students to cope with academic workload and reduce stress, they need to develop effective time management skill, improve on their level of concentration to their studies, and avoid use of drugs, among others.

\section{Counselling Implication}

The goal of Guidance and counselling within the educational setting is to facilitate students' psychological well-being that could enhance positive academic achievement and improved performance of students.

$\checkmark$ The counsellor could discourage the use of drugs among students with the use of systematic desensitization technique. This techniques if appropriately used would encouraged the addicted students voluntarily dissociate his/herself from using drugs.

$\checkmark$ The counsellor should encouraged adequate rewarding of students success and also sees that their failures are effectively corrected. From the psychological point of view, motivation is vital in anything one does for the attainment of psychologicalwell-being.

$\checkmark$ The students' activities should be appropriately scheduled by counsellors to avoid module-up and for optimal performance. This is because the future of the country depends on the psychological, social, moral and emotional well-being of these adolescents.

$\checkmark$ The counsellor should organize series of training skills that could discourage use of substance and reduce academic stress in students hence, allow them to adopt some coping strategies in the academic environment.

$\checkmark$ The counsellor could also adopt the use of group therapy in handling behaviour disorder in students. The advantages of group therapy include; serves as social support, source of learning useful new behaviour such as, how to say Yes or No and still not offending other person. It can also lead individuals towards insights into their own behaviour, among others.

$\checkmark$ The counsellorsshould give professional advice to the government on the procedure through which the academic environment could be made conducive enough for the students. This could enhance their adequate adjustment.

\section{Recommendation}

\section{Base on the findings, the following recommendation are given:}

There is need for changes in the academic plan and procedure so as to reduce cumbersome nature of educational activities in the academic environment. This will go a long away in reducing academic stress on students and at the same time improve their psychological well-being. For examples where the students have too many clashes in their courses with 
other lecturers, where students receive their lecturers in different environment far from each other, where classrooms are not conducive for lectures among others. These situations need better improvement.

$\checkmark$ There isneed to train the students how to develop coping strategies to deal with academic stress. This could be done through sensitizationsprogramme and several workshops.

$\checkmark$ Seminars to assist students disabuse the use of substance or drugs and its nasty negative effects could be organized for students.

$\checkmark$ There is also the need for rehabilitation Centre for students who have addicted to drug and regular counselling should be provided for them at the Centre. This will assist them in sanitizing the society from crimes that could results through these categories of students.

$\checkmark$ Advocacy programme, giving out handbills to youths, media programmes, playlets, drama, among others; could enhanced to teach coping mechanism to balance up the students psychological wellbeing. These must be provided at regular interval.

$\checkmark$ Covering team building and interaction skills, conflict resolution skills, entrepreneur skills are generally accepted by all categories of respondents as skills that should be emphasized for effective personality counselling.

\section{References:}

1. Baron, R. (1988).The Development of a Concept of Psychological Well-being.Unpublished Doctoral dissertation.Rhodes University, South African.

2. Bukoye, R.O. (2004). Stress and its Management in academic Environment. Unpublished speech presentation. Pp. 5-10.

3. Fairbrother, K. and Warn, J. (2003). Workplace Dimension Stress and Job Satisfaction, J. of Management Psychology. 18(1), 10-25.

4. Frazer, G.H (2011). The Social and Academic Stress Scale: Identification and rated Importance of a Academic Stressors. Psychological Reports. 60(2), 412-430.

5. Gesse, E. and Moss, O. (1996). Review of the Satisfaction with Life Scale Assessment, 5. 164- 172.

6. Ige, A.O. (1990). Drug Abuse and Discipline among school - going youth. A book of Reading University of Ilorin Teaching Hospital, Ilorin. Pg. 86-87.

7. Kessler, p. (2001).Social and Cultural Factors Affecting the mental Health of the Aged. American Journal of Health. 36, 680-685.

8. Kobasah, S.C. (2009). Stressful Life Events, Personality and Health: An Inquiry into Hardiness. Journal of Personality and Social Psychology. 37,1-11. 
9. Lakaeve, L. (2006). Academic Stress Respond Scale.

10. Lakaeve, L. (2010). Revise Academic Stress Response Scale (LASRS).

11. Lapan, R.T., Gysbers, N.C. and Sun, Y. (1997).The Impact of More fully Implemented Guidance Programme on the School Experiences of High School Students.A state wide evaluation study.Journal of Counselling and Development, 75,292-320.

12. Mangen, D. and Peterson, A. (1982). Research Instrument in Social Gerontology: Vol 1, Clinical and Social Psychology. Pp 195-248.

13. Murphy, G.C. (2000). And athansou, J.A. (1999). The effect of Unemployment on mental Health.Journal of Occupational and Organizational Psychology. 72,83-99.

14. Murphy, M.C. (2002). Stressors on the College Campus: A Comparison of 1985-1993.

15. Ndu, K.C. (2002). Psychology Understanding of Peoples behaviour $3^{\text {rd }}$ Ed.New York Roneharty and Winst.

16. Papalia, D.E. and Feldman, R.D. (2004).Human Development. $9^{\text {th }}$ ed. New York McGraw.

17. Payne, C.O. (2000). Stress and substance intake on body metabolic. Paper presentation to group of Nursing Students in South African: pg. 15

18. Pinto, Z. (1994). An Adrenalin Stress and Stressor index as Criteria measure in Work Environment. Nursing Research Journal, 17,295-340.

19. Reber, A.S. and Reber E.S. (2001).Dictionary of Psychology. London: Penguin Books.

20. Ryff, C.D. (1989). Happiness is Everything or is it? Explorations on the meaning of Psychological well-being.Journal of personality and social psychology.57(6) 1069- 1086.

21. Saka, B.I. (2010) Response Model of Stress and Psychological approaches to arresting it.Journal of Teacer Education Trend (JOTET) Vol.3 No. 1. Pg. 68-69.

22. Sax, L.J. (1997).Health Trends among College Freshman.Journal of American College of health, 45, 252-262.

23. Skinner, B.F. (1982). The Stress and Stressor Concept in Every Life Situation.

24. Visser, M. (2008).Substance Abuse and Psychological Well-being of South African Adolescents. South African Journal of Psychology.Vol. 37. No. 3pp. 595-615.

25. Walter, J.M. (2001). Buzzin: Pcp use in Philadelphia.

26. Warn, R. (2003). The trend of anxiety and substeence abuse on emotional stability.Upipublish

Thsis. 
27. Yahaya, L.A. (1998). Severity of stress induced factors among students in tertiary institutions in Ilorin metropolis. The Nigerian Journal of Guidance and counselling.Vol. 6 No. 1\&2.Pg 89-92.

28. Zoman, (2009). An Appraisal Processes in Emotion: theory Methods and Research Canary, MC: oxford University Press. 